\title{
The Kinetic Investigation and Optimization of the Processes of Larch Arabinogalactane Hydrolysis in the Presence of Dissolved and Solid Acid Catalysts
}

\author{
Olga V. Yatsenkova, Andrei M. Skripnikov, \\ Svetlana A. Kozlova and Boris N. Kuznetsov* \\ Institute of Chemistry and Chemical Technology SB RAS \\ FRC "Krasnoyarsk Science Center SB RAS" \\ 50/24 Akademgorodok, Krasnoyarsk, 660036, Russia
}

Received 24.12.2017, received in revised form 13.01.2018, accepted 19.03.2018

The influence of the temperature and the reaction time of larch arabinogalactan (AG) hydrolysis in the presence of dissolved mineral acids $\mathrm{H}_{2} \mathrm{SO}_{4}$ and $\mathrm{HCl}$, as well as solid acid catalysts Amberlyst 15 , acid-modified SBA-15 and Sibunit-4 on the rate of formation of arabinose and galactose was studied. The rate constants of monosaccharides formation are increased in the series of catalysts: Sibunit-4 $\left(150^{\circ} \mathrm{C}\right)<\mathrm{SBA}-15\left(150^{\circ} \mathrm{C}\right)<$ Amberlyst $15\left(150^{\circ} \mathrm{C}\right)<0,1 \mathrm{M} \mathrm{H}_{2} \mathrm{SO}_{4}\left(130^{\circ} \mathrm{C}\right)<0,1 \mathrm{M} \mathrm{HCl}\left(130^{\circ} \mathrm{C}\right)$. The activation energy of the reaction of arabinose formation $(65-91 \mathrm{~kJ} / \mathrm{mol})$ is lower than that of galactose (112-140 kJ /mol). The composition of soluble products of acid hydrolysis of arabinogalactan is studied by gas chromatography.

The process of arabinogalactan hydrolysis in the presence of dissolved and solid acid catalysts was optimized by the calculation methods. The optimal parameters of processes at which a degree of arabinogalactan conversion close to $100 \%$ are established.

Keywords: larch arabinogalactan, catalysts, $\mathrm{H}_{2} \mathrm{SO}_{4}, \mathrm{HCl}$, acid-modified solid catalysts, hydrolysis, kinetics, optimization, conversion, arabinose, galactose.

Citation: Yatsenkova O.V., Skripnikov A.M., Kozlova S.A., Kuznetsov B.N. The kinetic investigation and optimization of the processes of larch arabinogalactane hydrolysis in the presence of dissolved and solid acid catalysts, J. Sib. Fed. Univ. Chem., 2018, 11(2), 167-183. DOI: 10.17516/1998-2836-0066.

(C) Siberian Federal University. All rights reserved

* Corresponding author E-mail address: yatsenkova@icct.ru 


\title{
Кинетическое исследование и оптимизация \\ процессов гидролиза арабиногалактана лиственницы \\ в присутствии растворенных \\ и твердых кислотных катализаторов
}

\author{
О.В. Яценкова, А.М. Скрипников, \\ С.А. Козлова, Б.Н. Кузнецов \\ Институт химии и химической технологии СО РАН \\ ФИЦ «Красноярский научный центр СО РАН» \\ Россия, 660036, Красноярск, Академгородок, 50/24
}

Изучено влияние температуры и продолжительности гидролиза арабиногалактана (АГ) лиственницы в присутствии растворенных минеральных кислот $\mathrm{H}_{2} \mathrm{SO}_{4}$ и $\mathrm{HCl}$, а также твердых кислотных катализаторов Amberlyst 15, кислотномодифицированных SBA-15 и Сибунит-4 на скорость образования арабинозы и галактозы. Константы скорости образования моносахаров увеличиваются в ряду катализаторов: Сибунит-4 $\left(150{ }^{\circ} \mathrm{C}\right)<\mathrm{SBA}-15\left(150{ }^{\circ} \mathrm{C}\right)<$ Amberlyst $15\left(150{ }^{\circ} \mathrm{C}\right)<0,1 \mathrm{M} \mathrm{H}_{2} \mathrm{SO}_{4}\left(130{ }^{\circ} \mathrm{C}\right)<0,1 \mathrm{M} \mathrm{HCl}\left(130{ }^{\circ} \mathrm{C}\right)$. Значения энергии активации реакции образования арабинозы (65-91 кДж/моль) ниже, чем галактозы (112-140 кДж/моль). Методом газовой хроматографии изучен состав растворимых продуктов кислотного гидролиза арабиногалактана.

Расчетными методами проведена оптимизация процесса гидролиза арабиногалактана в присутствии растворенного и твердого кислотных катализаторов. Установлень оптимальные режимные параметры прочессов, при которых достигается близкая к $100 \%$ степень конверсии арабиногалактана.

Ключевые слова: арабиногалактан лиственницы, $\mathrm{H}_{2} \mathrm{SO}_{4}, \mathrm{HCl}$, кислотномодифицированные твердые катализаторы, гидролиз, кинетика, оптимизация, конверсия, арабиноза, галактоза, SBA-15.

\section{Введение}

Древесина лиственницы сибирской, произрастающей в Красноярском крае, содержит до 15 \% мас. водорастворимого полисахарида арабиногалактана [1]. Главная цепь макромолекулы арабиногалактана (рис. 1) состоит из звеньев галактозы, а боковые - из звеньев галактозы и арабинозы, единичных звеньев арабинозы и уроновых кислот [2].

Арабиногалактан является биологически активным веществом, обладающим широким спектром иммунобиологической активности: гастро- и гепатопротекторным, иммуномодулирующим, мембранотропным, антимутагенным и т.д. [3, 4]. Изучаются возможности использования АГ для синтеза новых лекарственных препаратов и ценных химических веществ [5].

В последние годы возник интерес к изучению процессов гидролиза арабиногалактана для получения растворов моносахаров. Мономеры D-галактоза и L-арабиноза в настоящее время 


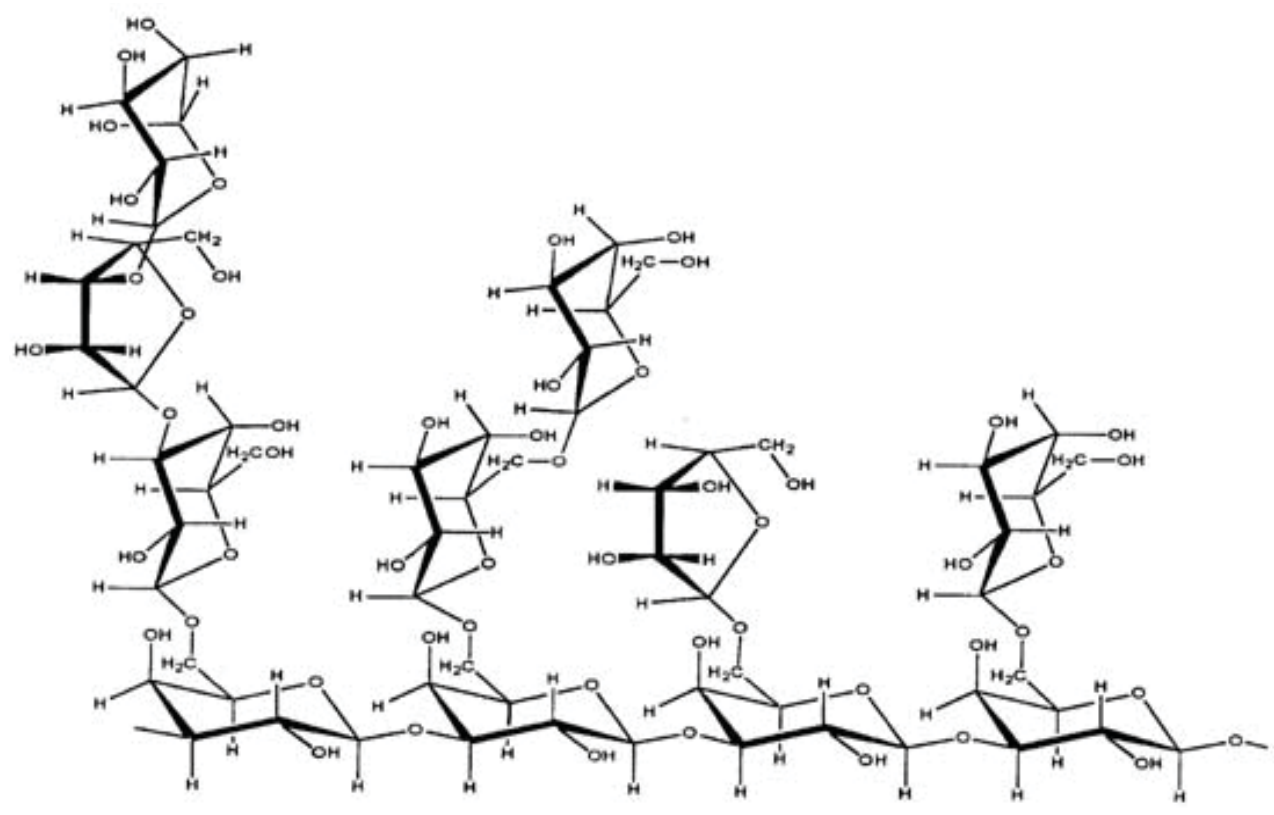

Рис. 1. Структура арабиногалактана

Fig. 1. Structure of arabinogalactan

востребованы как специальные сахара в фармацевтической и косметической промышленности, медицине [6]. Галактозу используют как питательную среду для поддержания жизнеспособности нервных клеток, в качестве контрастно-диагностического средства при проведении ультразвуковых исследований, в лекарственных препаратах, проявляющих цитотоксические и противовоспалительные свойства $[7,8]$. Арабинозу применяют как полупродукт в синтезе витамина $\mathrm{B}_{2}$ и противовирусных препаратов [9].

Имеются сведения [10] о влиянии условий процесса кислотного гидролиза АГ на скорость образования моносахаров. Установлено, что гидролитическая устойчивость арабиногалактана в растворе $\mathrm{HCl}$ в значительной степени зависит от $\mathrm{pH}$ и температуры реакции. Полный гидролиз арабиногалактана до эквивалентного количества арабинозы и галактозы осуществлен при температуре $90{ }^{\circ} \mathrm{C}, \mathrm{pH}=1$ и продолжительности 23 ч.

Поиск экологически безопасных способов химической переработки растительных полимеров стимулирует применение твердых кислотных катализаторов вместо токсичных и коррозионно-активных минеральных кислот [11]. Кроме того, использование твердых кислотных катализаторов вместо растворов кислот позволяет исключить проблему отделения катализатора от продуктов реакции.

Показана возможность селективного гидролиза АГ с выходом арабинозы до 95 \% при температуре $90{ }^{\circ} \mathrm{C}$ в присутствии твердого кислотного катализатора Smopex-101 [12]. При этом не образуются продукты дегидратации сахаров (фурфурол и 5-гидроксиметилфурфурол), а часть звеньев галактозы макромолекулы АГ остается негидролизованной.

В присутствии твердых кислотных катализаторов, приготовленных на основе мезопористого углерода, гидролиз АГ при температуре $185^{\circ} \mathrm{C}$ протекает с образованием равных коли- 
честв арабинозы и галактозы, причем в гидролизатах присутствуют в больших количествах фурфурол, 5-гидроксиметилфурфурол и гуминовые вещества [13].

Анализ литературы показывает, что твердые кислотные катализаторы могут стать альтернативой минеральным кислотам в гидролизе полисахаридов при условии их достаточно высокой активности, селективности, устойчивости к воздействию водной среды [14].

Целью настоящей работы стал поиск оптимальных условий протекания реакции гидролиза арабиногалактана древесины лиственницы в присутствии растворенных катализаторов $\mathrm{H}_{2} \mathrm{SO}_{4}$ и $\mathrm{HCl}$, а также твердых катализаторов Amberlyst 15, SBA-15, Сибунит-4, содержащих

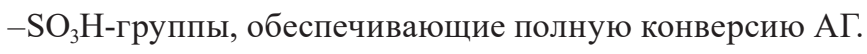

\section{Экспериментальная часть}

Исходные материалы и реактивы, катализаторы

В качестве исходного сырья использовали арабиногалактан древесины лиственницы сибирской - препарат «Фибролар С» производства ООО «Химия древесины» (Иркутск, Россия). Элементный состав арабиногалактана (углерод 44,4 \%, водород 6,7 \%, кислород 48,9 \%) определяли на анализаторе Flash EA-1112 (Thermo Quest Italia).

Информация о строении и размерах частиц арабиногалактана получена с использованием растрового электронного микроскопа «ТМ-1000 НITACНI» (Япония) с ускоряющим напряжением $15 \mathrm{kV}$ и с увеличением от 100 до 10000 крат с разрешением 30 нм. Электронномикроскопический снимок образца арабиногалактана «Фибролар С» приведен на рис. 2.

Исходный арабиногалактан состоит из агрегированных и одиночных частиц различной формы и размеров. Преобладают частицы глобулярной формы с диаметром от 5 до 10 мкм. Также присутствуют агломераты частиц, размер которых достигает 100 мкм.

В качестве растворенных катализаторов гидролиза АГ использовали серную кислоту квалификации «Хч» (ГОСТ 4204-77, Россия) и соляную кислоту («хч», ГОСТ 3118-77, Россия). Все растворы готовили с применением дистиллированной воды (ГОСТ 6709-72).

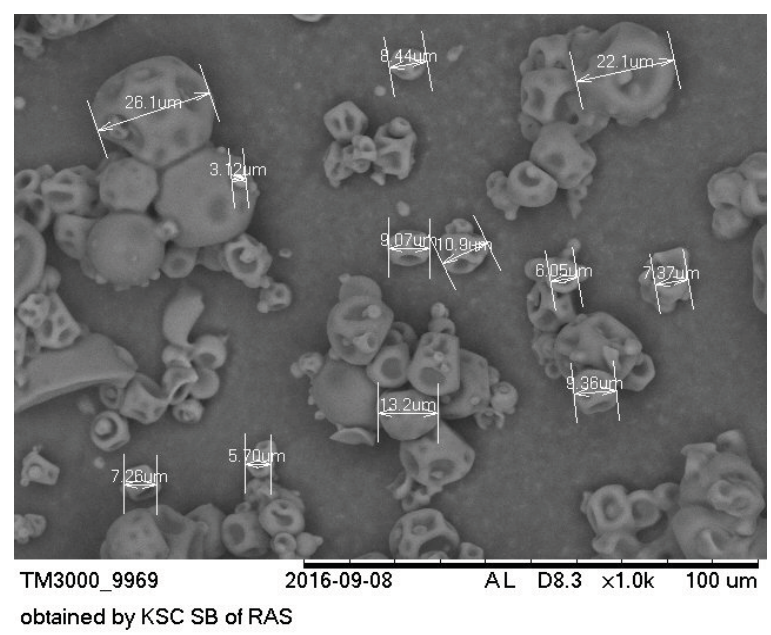

Рис. 2. Электронно-микроскопический снимок образца арабиногалактана («Фибролар С»)

Fig. 2. SEM images of a sample of arabinogalactan ("Fibrolar C") 
Таблица 1. Текстурные характеристики катализаторов

Table 1. Texture characteristics of the catalysts

\begin{tabular}{|l|c|c|c|c|}
\hline \multicolumn{1}{|c|}{ Катализатор } & $\mathrm{S}_{\mathrm{BET}}, \mathrm{M}^{2} / \Gamma$ & $\mathrm{V}_{\text {пор }}, \mathrm{cm}^{3} / \Gamma$ & $\mathrm{D}_{\text {пор }}, \mathrm{Hм}$ & $\begin{array}{c}\mathrm{C}_{\text {кисл. групп, }} \\
\text { ммоль } / \Gamma\end{array}$ \\
\hline Исходный Сибунит-4 & 379 & 0,63 & 6,6 & 0,04 \\
\hline $\begin{array}{l}\text { Кислотномодифицированный } \\
\text { Сибунит-4 }\end{array}$ & 267 & 0,36 & 5,3 & 0,48 \\
\hline Исходный SВА-15 & 550 & 0,82 & 5,9 & около 0,05 \\
\hline $\begin{array}{l}\text { Кислотномодифицированный } \\
\text { SВА-15 }\end{array}$ & 417 & 0,59 & 5,6 & 0,71 \\
\hline
\end{tabular}

В качестве твердых кислотных катализаторов гидролиза АГ использовали макропористую ионообменную смолу на основе сополимера стирола и дивинилбензола Amberlyst 15 dry (Acros organics) и содержащие $\mathrm{SO}_{3} \mathrm{H}-г$ руппы SBA-15 и Сибунит-4.

Кислотное модифицирование углеродного мезопористого материала Сибунит-4 проводили, обрабатывая его сначала водным раствором азотной кислоты («хч», ГОСТ 4461-77, Россия), а затем дополнительно дымящейся серной кислотой («хч», ТУ 2612-005-56853252-2003, Россия) по методике [15].

Кислотное модифицирование мезопористого SBA-15 включало прививку 3-меркаптопропилтриметоксисилана $\left(\mathrm{C}_{6} \mathrm{H}_{16} \mathrm{O}_{3} \mathrm{SSi}\right.$ Aldrich, Cat.: 175617) с последующим окислением меркаптогрупп до групп - $\mathrm{SO}_{3} \mathrm{H}$ с использованием $30 \%$-ного пероксида водорода (ГОСТ 177-88, Россия) [16-18].

Текстурные свойства модифицированных образцов были исследованы методом низкотемпературной адсорбции $\mathrm{N}_{2}$ на установке ASAP-2420 (Micrometritics, США) при T=98 К в интервале относительных давлений $\left(\mathrm{P}^{\mathrm{P}} \mathrm{P}^{0}\right)$ 0,06-0,99 с шагом 0,015. Удельную площадь поверхности рассчитывали по модели ВЕТ в интервале $\mathrm{P} / \mathrm{P}^{0} 0,06-0,25$, внутренний объем пор по методу «Single Point BET», а распределение пор по размерам получали по уравнению изотермы ВЈН.

Концентрацию кислотных групп на поверхности катализаторов определяли кислотноосновным титрованием гидроксидом натрия.

В результате прививки функциональных групп для всех образцов катализаторов наблюдается закономерное уменьшение площадей удельной поверхности и размеров пор. Некоторые характеристики катализаторов приведены в табл. 1.

\section{Методика гидролиза арабиногалактана растворами кислот}

Гидролиз АГ в присутствии растворенных кислотных катализаторов проводили в стеклянном реакторе при атмосферном давлении и температуре $90-100{ }^{\circ} \mathrm{C}$. Навеску воздушносухого арабиногалактана в количестве 0,75 г помещали в реактор, затем приливали 150 мл раствора $0,1 \mathrm{M} \mathrm{H}_{2} \mathrm{SO}_{4}$ или 0,1M HCl. Реакционную смесь выдерживали в течение 60-420 мин при интенсивности перемешивания 14 об/с. По истечении заданного времени полученный гидролизат анализировали на содержание сахаров и примесей. Гидролиз АГ при температуре $130{ }^{\circ} \mathrm{C}$ проводили в автоклаве. 
Методика гидролиза арабиногалактана

в присутствии твердых кислотных катализаторов

Гидролиз арабиногалактана в присутствии твердых кислотных катализаторов проводили в водной среде при температуре $100-150^{\circ} \mathrm{C}$ во вращающемся стальном автоклаве с внутренней фторопластовой пробиркой объемом 35 мл, помещенном в металлический воздушный термостат. Скорость вращения автоклава составляла 11 об/мин. Смесь арабиногалактана $(0,075$ г) и твердого катализатора (0,075 г) помещали в пробирку и заливали 15 мл дистиллированной воды. Продолжительность гидролиза варьировали от 60 до 360 мин.

По истечении заданного времени пробирку охлаждали и полученный гидролизат отделяли от твердого катализатора на воронке Бюхнера на бумажном фильтре под вакуумом. Катализатор промывали водой и высушивали в сушильном шкафу при температуре $103{ }^{\circ} \mathrm{C}$, а гидролизат анализировали на содержание сахаров и примесей.

\section{Анализ состава гидролизатов арабиногалактана}

Индивидуальный состав и содержание моносахаров в гидролизатах АГ исследовали с использованием газового хроматографа «VARIAN-450 GC» с пламенно-ионизационным детектором на капиллярной колонке VF-624 ms длиной 30 м, внутренним диаметром 0,32 мм. Пробу гидролизата предварительно подвергали дериватизации по методике [19] с образованием триметилсилильных производных. В качестве силилирующего реагента использовали смесь триметилхлорсилана и гексаметилдисилазана в среде пиридина, а в качестве внутреннего стандарта - сорбит. Идентификацию пиков проводили, применяя ранее установленные для данных условий хроматографирования значения времен удерживания $t_{R}$ таутомерных форм моносахаров. Рассчитывали отношение площадей каждого характеристического пика моносахарида к площади пика внутреннего стандарта - сорбита $\left(\mathrm{S}_{\mathrm{i}} / \mathrm{S}_{\mathrm{c \tau}}\right)$. По этим соотношениям с помощью градуировочного графика находили массу каждого моносахарида в пробе гидролизата.

Для определения количественного содержания микропримесей фурфурола, 5-гидроксиметилфурфурола (5-ГМФ) и левулиновой кислоты гидролизаты нейтрализовали карбонатом натрия до рН 5. Пробу гидролизата три раза последовательно экстрагировали этилацетатом. В делительную воронку вносили пипеткой 2 мл пробы, затем добавляли 2 мл этилацетата. Воронку интенсивно встряхивали и давали отстояться до разделения фаз, после чего отделяли фазу этилацетата. К 1 мл этилацетатного экстракта добавляли 0,4 мл антрацена (внутренний стандарт) и проводили хроматографирование. Для расчета содержания левулиновой кислоты, фурфурола и 5-ГМФ использовали градуировочные графики.

В качестве стандартов для анализа гидролизатов брали арабинозу (Panreac, Германия), галактозу (Panreac, Германия), сорбит (Panreac, Германия), антрацен (Sigma-Aldrich, США), фурфурол (Sigma-Aldrich, США), 5-гидроксиметил-2-фуральдегид (Sigma-Aldrich, США), левулиновую кислоту (Sigma-Aldrich, США).

\section{Кинетический анализ}

Реакцию гидролиза арабиногалактана принято относить к реакциям «псевдо» первого порядка [20]. В кинетическом анализе опускаются реакции образования олигосахаров из полисахарида и учитываются только реакции образования моносахаров [21].

$$
-172-
$$


Скорость реакции первого порядка в общем виде выражается уравнением [10]

$$
v=d c / d \tau=k c \text {. }
$$

Концентрации моносахаров описываются дифференциальными уравнениями:

$$
\begin{aligned}
& \frac{d \mathrm{C}_{\mathrm{A}}}{d \tau}=k_{\mathrm{A}} \cdot \mathrm{C}_{\mathrm{A}} ; \\
& \frac{d \mathrm{C}_{\Gamma}}{d \tau}=k_{\Gamma} \cdot \mathrm{C}_{\Gamma},
\end{aligned}
$$

где $\mathrm{C}_{\mathrm{A}}$ и $\mathrm{C}_{\Gamma}$ - текущие концентрации арабинозных и галактозных звеньев в гидролизате; $\mathrm{k}_{\mathrm{A}}$ и $\mathrm{k}_{\Gamma}$ - константы скорости образования арабинозы и галактозы в реакции гидролиза АГ.

После интегрирования уравнений (2) и (3) с начальным условием $\tau=0, \mathrm{C}_{\mathrm{A}}=0$ и $\mathrm{C}_{\Gamma}=0$ вычисляются константы скорости реакции образования моносахаров:

$$
\begin{aligned}
& k_{A}=-\ln \left(1-C_{A} / C_{A}^{\prime}\right) / \tau ; \\
& k_{\Gamma}=-\ln \left(1-C_{\Gamma} / C_{\Gamma}^{\prime}\right) / \tau,
\end{aligned}
$$

где $\mathrm{C}_{\mathrm{A}}^{\prime}$ и $C_{\Gamma}^{\prime}$ - расчетные концентрации арабинозы и галактозы в гидролизате исходя из условия соответствия начального количества арабинозных и галактозных звеньев в арабиногалактане конечному количеству мономеров арабинозы и галактозы в случае полного гидролиза АГ.

\section{Результаты и обсуждения}

Гидролиз арабиногалактана

в присутствии растворенных катализаторов

Каталитические свойства растворенных катализаторов $0,1 \mathrm{M} \mathrm{H}_{2} \mathrm{SO}_{4}$ и $0,1 \mathrm{M} \mathrm{HCl}$ в процессе гидролиза арабиногалактана изучены в интервале температур $90-130{ }^{\circ} \mathrm{C}$. Начальная концентрация АГ во всех экспериментах составляла 5 г/л.

На рис. 3 приведена газовая хроматограмма гидролизата, полученного гидролизом арабиногалактана при $100{ }^{\circ} \mathrm{C}$ в присутствии катализатора $0,1 \mathrm{M} \mathrm{H}_{2} \mathrm{SO}_{4}$. Хроматограмма включает пики содержащихся в пробе гидролизата таутомеров арабинозы и галактозы.

Установлено, что при температуре процесса гидролиза арабиногалактана $90{ }^{\circ} \mathrm{C}$ и продолжительности 420 мин в присутствии катализаторов $0,1 \mathrm{M} \mathrm{HCl}$ и $0,1 \mathrm{M} \mathrm{H}_{2} \mathrm{SO}_{4}$ суммарное содержание галактозы и арабинозы в гидролизатах не превышает 2,2 г/л.

При температуре $100{ }^{\circ} \mathrm{C}$ и продолжительности гидролиза 360 мин концентрации галактозы и арабинозы в присутствии катализатора $0,1 \mathrm{M} \mathrm{H}_{2} \mathrm{SO}_{4}$ составили 4,3 и 0,6 г/л соответственно (рис. $4 A$ ), что свидетельствует о полном гидролизе арабиногалактана. Однако в аналогичных условиях гидролиза в присутствии катализатора $0,1 \mathrm{M} \mathrm{HCl}$ максимальные концентрации галактозы и арабинозы не превысили 2,0 и 0,5 г/л (рис. $5 A$ ).

При повышении температуры процесса от 100 до $130{ }^{\circ} \mathrm{C}$ увеличивается концентрация галактозы в гидролизатах в присутствии как сернокислотного, так и солянокислотного катализаторов. Гидролизаты, полученные при продолжительности процесса 90 мин, содержат 4,4 г/л галактозы и 0,6 г/л арабинозы (рис. 45 и 55 ), что свидетельствует о полном гидролизе АГ.

$$
-173-
$$




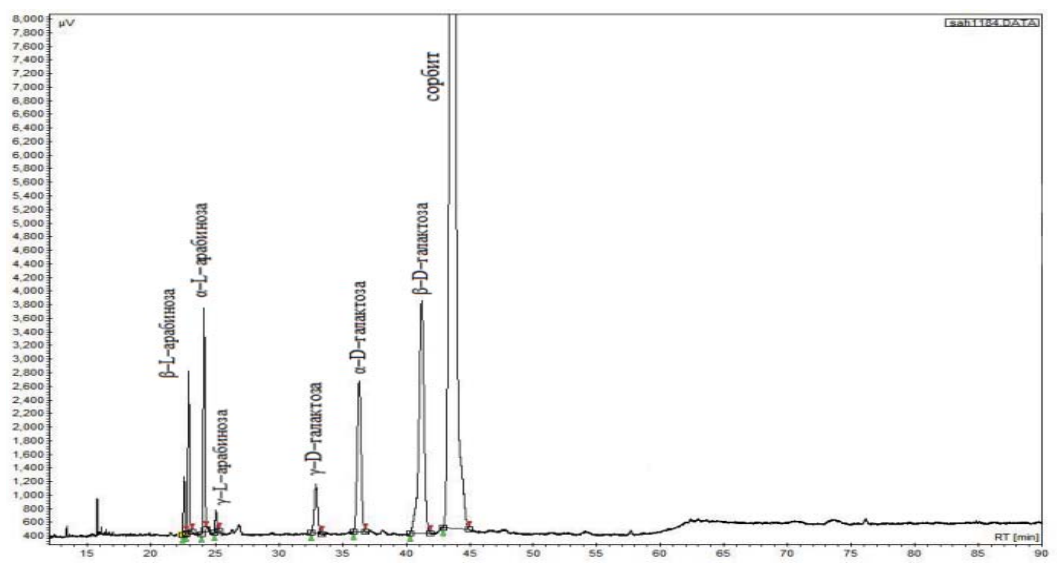

Рис. 3. Хроматограмма гидролизата, полученного гидролизом арабиногалактана из древесины лиственницы при температуре $100{ }^{\circ} \mathrm{C}$ и продолжительности 360 мин (катализатор 0,1 $1 \mathrm{M} \mathrm{H}_{2} \mathrm{SO}_{4}$, сорбит внутренний стандарт)

Fig. 3. Chromatogram of hydrolyzate obtained by hydrolysis of larch arabinogalactan at $100^{\circ} \mathrm{C}$ and time $360 \mathrm{~min}$ (catalyst $0,1 \mathrm{M} \mathrm{H}_{2} \mathrm{SO}_{4}$, sorbitol - internal standard)

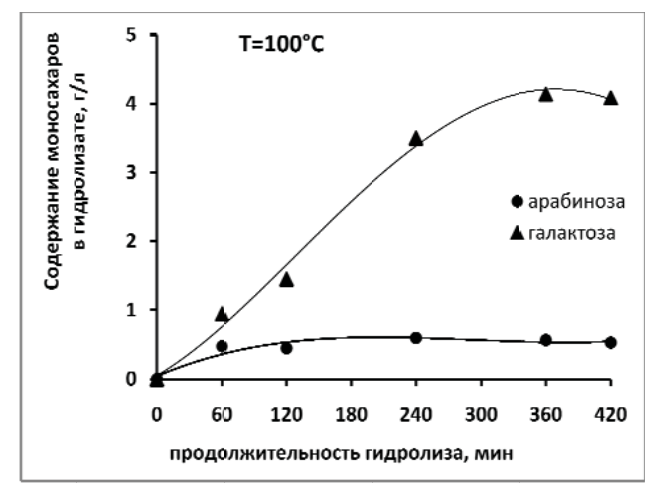

A

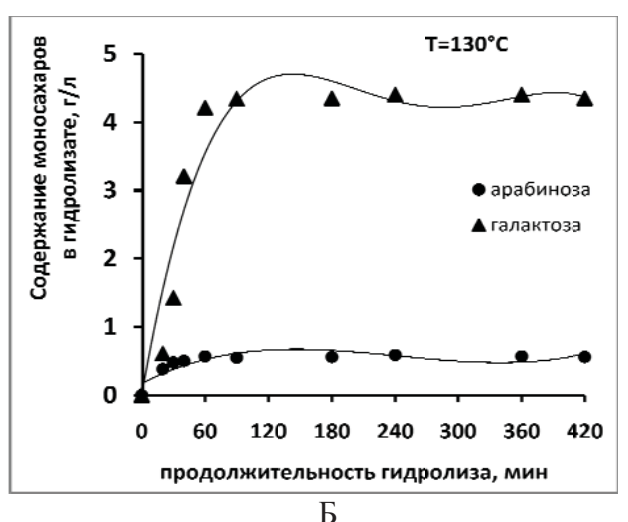

Б

Рис. 4. Влияние температуры и продолжительности гидролиза арабиногалактана в присутствии катализатора $0,1 \mathrm{M} \mathrm{H}_{2} \mathrm{SO}_{4}$ на содержание моносахаров в гидролизате

Fig. 4. Influence of temperature and reaction time of arabinogalactan hydrolysis in the presence of $0,1 \mathrm{M} \mathrm{H}_{2} \mathrm{SO}_{4}$ catalyst on the content of monosaccharides in the hydrolyzate

\section{Гидролиз арабиногалактана}

в присутствии твердых кислотных катализаторов

Каталитические свойства твердых кислотных катализаторов Amberlyst 15, модифицированных Сибунита-4 и SBA-15 в гидролизе арабиногалактана исследованы при температурах $100-150{ }^{\circ} \mathrm{C}$.

Установлено, что все гидролизаты арабиногалактана, полученные при температуре $100{ }^{\circ} \mathrm{C}$ в присутствии твердых кислотных катализаторов, содержат больше арабинозы, чем галактозы. Вероятно, при этой температуре в присутствии твердых катализаторов, содержащих

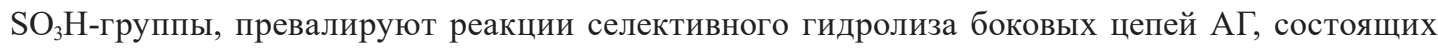




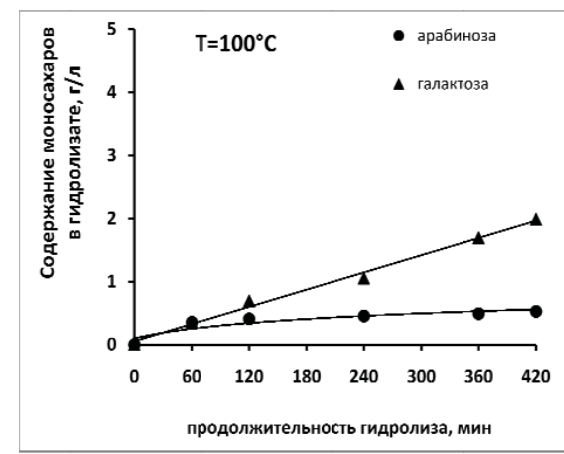

A

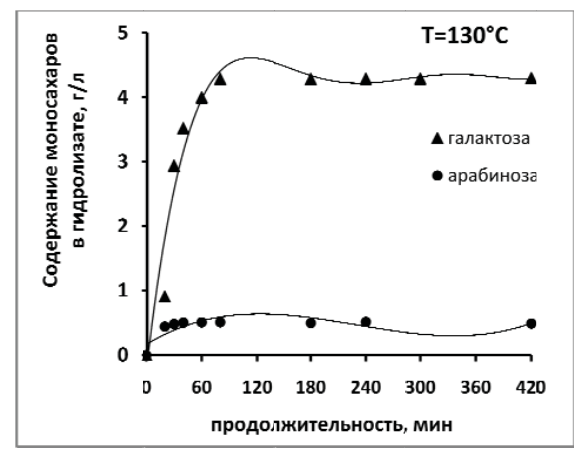

Б

Рис. 5. Влияние температуры и продолжительности гидролиза арабиногалактана в присутствии катализатора $0,1 \mathrm{M} \mathrm{HCl}$ на содержание моносахаров в гидролизате

Fig. 5. Influence of temperature and reaction time of arabinogalactan hydrolysis in the presence of $0,1 \mathrm{M} \mathrm{HCl}$ catalyst on the content of monosaccharides in the hydrolyzate
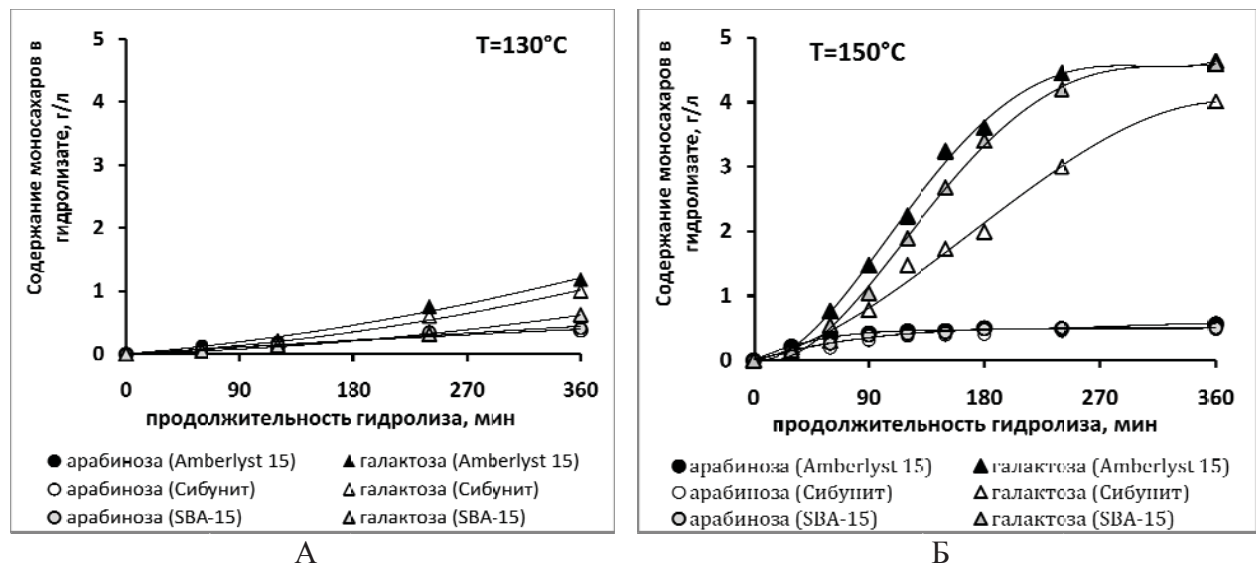

Рис. 6. Влияние природы твердых кислотных катализаторов, температуры и продолжительности гидролиза арабиногалактана на содержание моносахаров в гидролизатах

Fig. 6. Influence of the nature of solid acid catalysts, temperature and time of arabinogalactan hydrolysis on the content of monosaccharides in hydrolysates

преимущественно из звеньев арабинозы [12]. Повышение температуры процесса до $130{ }^{\circ} \mathrm{C}$ способствует протеканию реакции гидролиза основной цепи макромолекулы АГ, приводящей к увеличению содержания галактозы в гидролизатах.

В присутствии катализатора Amberlyst 15 при температуре гидролиза арабиногалактана $130{ }^{\circ} \mathrm{C}$ и продолжительности процесса 360 мин содержание галактозы и арабинозы в гидролизате не превышает 1,2 и 0,4 г/л соответственно (рис. $6 A$ ).

Увеличение температуры гидролиза АГ до $150^{\circ} \mathrm{C}$ в присутствии катализаторов Amberlyst 15 и SBA-15 приводит к повышению содержания галактозы и арабинозы в гидролизате до 4,3 и 0,6 г/л при продолжительности процесса 240 мин (рис. 6Б). Это свидетельствует о полном гидролизе арабиногалактана в указанных условиях процесса. 
Гидролизаты, полученные при температуре $150{ }^{\circ} \mathrm{C}$, содержат «следовые» количества ( 0,001 г/л) продуктов вторичных превращений арабинозы и галактозы в фурановые соединения (фурфурол и 5-ГМФ).

\section{Кинетическое исследование реакиии гидролиза арабиногалактана}

Изучение кинетики процесса каталитического гидролиза арабиногалактана осуществлялось в интервале температур $90-150{ }^{\circ} \mathrm{C}$. Изменение концентрации арабинозы и галактозы в гидролизате использовали для расчета констант скорости образования моносахаров $\left(\mathrm{k}_{\mathrm{A}}, \mathrm{k}_{\Gamma}\right)$.

Рассчитанные значения констант скорости образования моносахаров в процессе гидролиза арабиногалактана в присутствии растворенных и твердых кислотных катализаторов приведены в табл. 2.

Из полученных данных следует, что $\mathrm{k}_{\mathrm{A}}$ и $\mathrm{k}_{\Gamma}$ увеличиваются в ряду катализаторов: Сибунит-4 $\left(150{ }^{\circ} \mathrm{C}\right)<\mathrm{SBA}-15\left(150{ }^{\circ} \mathrm{C}\right)<$ Amberlyst $15\left(150{ }^{\circ} \mathrm{C}\right)<0,1 \mathrm{M} \mathrm{H}_{2} \mathrm{SO}_{4}\left(130{ }^{\circ} \mathrm{C}\right)<0,1 \mathrm{M} \mathrm{HCl}$ $\left(130{ }^{\circ} \mathrm{C}\right)$. Вероятно, пониженная каталитическая активность Сибунита в гидролизе арабинога-

Таблица 2. Константы скорости и энергия активации образования моносахаров в процессе гидролиза арабиногалактана при различных температурах в присутствии катализаторов

Table 2. Rate constants and activation energy of monosaccharides formation in the process of arabinogalactan hydrolysis at different temperatures in the presence of catalysts

\begin{tabular}{|c|c|c|c|c|}
\hline $\begin{array}{l}\text { Температура } \\
\text { гидролиза, }{ }^{\circ} \mathrm{C}\end{array}$ & \multicolumn{2}{|c|}{$\begin{array}{c}\text { Константа скорости образования } \\
\text { моносахаров } 10^{-5} \mathrm{c}^{-1}\end{array}$} & \multicolumn{2}{|c|}{$\begin{array}{c}\text { Энергия активации, } \\
\text { кДж/моль }\end{array}$} \\
\hline \multicolumn{2}{|c|}{ арабиноза } & галактоза & арабиноза & галактоза \\
\hline \multicolumn{5}{|c|}{ катализатор 0,1 $\mathrm{M} \mathrm{H}_{2} \mathrm{SO}_{4}$} \\
\hline 90 & 7,2 & 1,5 & \multirow{3}{*}{65} & \multirow{3}{*}{112} \\
\hline 100 & 16,2 & 7,5 & & \\
\hline 130 & 60,2 & 60,3 & & \\
\hline \multicolumn{5}{|c|}{ катализатор 0,1M HCl } \\
\hline 90 & 4,7 & 1,2 & \multirow{3}{*}{81} & \multirow{3}{*}{124} \\
\hline 100 & 11,2 & 2,2 & & \\
\hline 130 & 67,3 & 70,0 & & \\
\hline \multicolumn{5}{|c|}{ катализатор Amberlyst 15} \\
\hline 100 & 0,5 & 0,06 & \multirow{3}{*}{91} & \multirow{3}{*}{134} \\
\hline 130 & 5,0 & 1,0 & & \\
\hline 150 & 16,0 & 9,7 & & \\
\hline \multicolumn{5}{|c|}{ катализатор модифицированный SBA-15 } \\
\hline 100 & 0,4 & 0,06 & \multirow{3}{*}{87} & \multirow{3}{*}{134} \\
\hline 130 & 3,7 & 0,5 & & \\
\hline 150 & 11,0 & 10,0 & & \\
\hline \multicolumn{5}{|c|}{ катализатор модифицированный Сибунит-4 } \\
\hline 100 & 0,3 & 0,02 & \multirow{3}{*}{90} & \multirow{3}{*}{140} \\
\hline 130 & 3,0 & 0,8 & & \\
\hline 150 & 9,2 & 4,1 & & \\
\hline
\end{tabular}



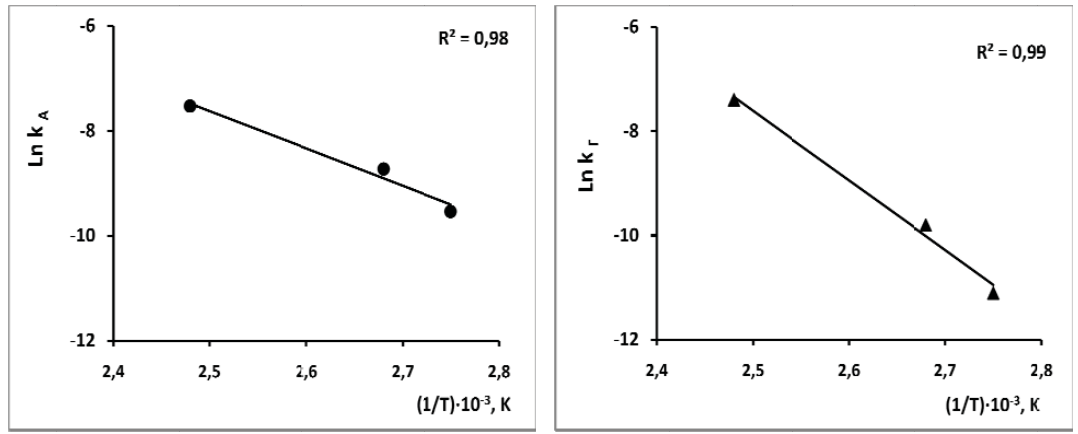

катализатор $0,1 \mathrm{M} \mathrm{H}_{2} \mathrm{SO}_{4}$
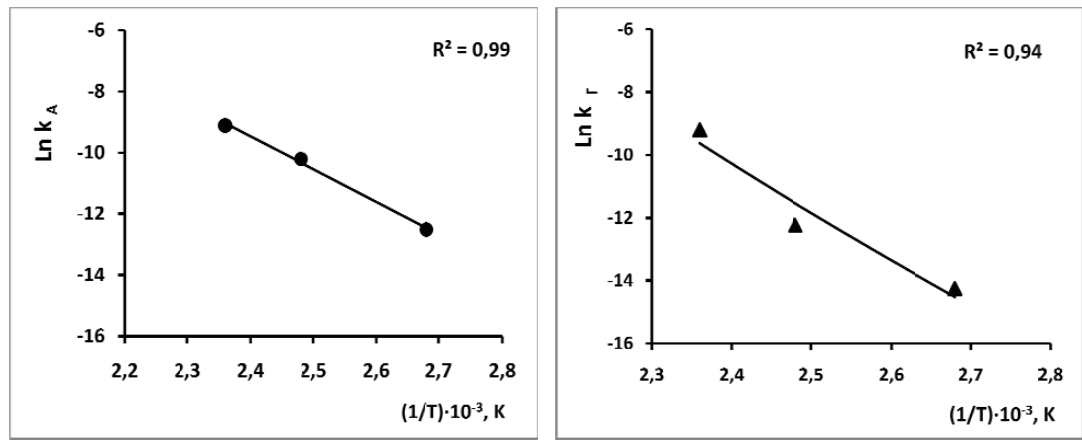

катализатор SBA-15

Рис. 7. Аррениусовские зависимости констант скоростей образования арабинозы и галактозы в процессе

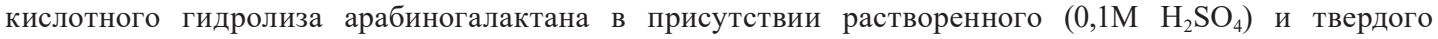
кислотного катализатора (SBA-15)

Fig. 7. Arrhenius dependences of the rate constants of arabinose and galactose formation in the process of arabinogalactan acid hydrolysis in the presence of dissolved $\left(0,1 \mathrm{M} \mathrm{H}_{2} \mathrm{SO}_{4}\right)$ and solid acid (SBA-15) catalysts

лактана объясняется невысоким содержанием кислотных групп в его составе и меньшей площадью удельной поверхности по сравнению с катализатором SBA-15 (табл. 1).

Значения энергии активации образования арабинозы и галактозы в процессе кислотного гидролиза арабиногалактана из древесины лиственницы определены из температурных зависимостей констант скоростей в координатах Аррениуса (рис. 7).

Как следует из представленных в табл. 2 данных, значения энергии активации реакции образования арабинозы (65-91 кДж/моль) ниже, чем галактозы (112-140 кДж/моль). Полученное значение энергии активации образования галактозы сопоставимо с известным из литературы [10] для процесса гидролиза АГ в присутствии $\mathrm{HCl}$ (135 кДж/моль).

\section{Математическая оптимизация процесса}

каталитического гидролиза арабиногалактана

Оптимизацию условий процесса каталитического гидролиза арабиногалактана проводили с использованием пакета прикладных программ Statgraphics Centurion XVI, блоки DOE и Nonlinear Regression [22].

Подбор оптимальных условий гидролиза АГ в присутствии растворенных и твердых кислотных катализаторов предполагал определение значений параметров процесса, обеспечи- 
вающих максимальную конверсию арабиногалактана. В качестве независимых переменных использованы следующие два фактора: $X_{1}$ - температура гидролиза (90-130 и 100-150), ${ }^{\circ} \mathrm{C}$; $X_{2}$ - продолжительность гидролиза (60-420), мин. Начальная концентрация арабиногалактана во всех экспериментах составляла 5 г/л. Результат процесса гидролиза характеризовали выходным параметром $Y$ - степенью конверсии арабиногалактана, \%.

Результаты, полученные с использованием матрицы планирования экспериментов в присутствии катализаторов $0,1 \mathrm{M} \mathrm{H}_{2} \mathrm{SO}_{4}$ и кислотномодифицированного $\mathrm{SBA}-15$, приведены в табл. 3 и 4.

Оптимизация процесса гидролиза АГ сводится к поиску в пределах изученного факторного пространства условий, обеспечивающих его максимальную степень конверсии: $Y \rightarrow$ max.

Таблица 3. Матрица планирования эксперимента по гидролизу арабиногалактана в присутствии катализатора $0,1 \mathrm{M} \mathrm{H}_{2} \mathrm{SO}_{4}$

Table 3. Matrix of experiment planning for the arabinogalactan hydrolysis in the presence of $0,1 \mathrm{M} \mathrm{H}_{2} \mathrm{SO}_{4}$ catalyst

\begin{tabular}{|c|c|c|c|}
\hline № опыта & $\begin{array}{c}\text { Температура гидролиза, }{ }^{\circ} \mathrm{C} \\
\left(\mathrm{X}_{1}\right)\end{array}$ & $\begin{array}{c}\text { Продолжительность } \\
\text { гидролиза, мин }\left(\mathrm{X}_{2}\right)\end{array}$ & $\begin{array}{c}\text { Степень конверсии } \\
\text { арабиногалактана, } \%(\mathrm{Y})\end{array}$ \\
\hline 1 & 90 & 60 & 9,6 \\
\hline 2 & 100 & 60 & 40,0 \\
\hline 3 & 130 & 60 & 95,6 \\
\hline 4 & 90 & 240 & 25,0 \\
\hline 5 & 100 & 240 & 81,9 \\
\hline 6 & 130 & 240 & 99,6 \\
\hline 7 & 90 & 420 & 32,5 \\
\hline 8 & 100 & 420 & 98,6 \\
\hline 9 & 130 & 420 & 99,6 \\
\hline
\end{tabular}

Таблица 4. Матрица планирования эксперимента по гидролизу арабиногалактана в присутствии катализатора SBA-15

Table 4. Matrix of experiment planning for the arabinogalactan hydrolysis in the presence of SBA-15 catalyst

\begin{tabular}{|c|c|c|c|}
\hline № опыта & $\begin{array}{c}\text { Температура гидролиза, }{ }^{\circ} \mathrm{C} \\
\left(\mathrm{X}_{1}\right)\end{array}$ & $\begin{array}{c}\text { Продолжительность } \\
\text { гидролиза, мин }\left(\mathrm{X}_{2}\right)\end{array}$ & $\begin{array}{c}\text { степень Конверсии } \\
\text { арабиногалактана, \% (Y) }\end{array}$ \\
\hline 1 & 100 & 120 & 1,6 \\
\hline 2 & 100 & 240 & 2,9 \\
\hline 3 & 100 & 360 & 3,8 \\
\hline 4 & 130 & 120 & 5,6 \\
\hline 5 & 130 & 240 & 20,5 \\
\hline 6 & 130 & 360 & 46,0 \\
\hline 7 & 150 & 120 & 90,0 \\
\hline 8 & 150 & 240 & 97,0 \\
\hline 9 & 150 & 360 & \\
\hline
\end{tabular}


Таблица 5. Результаты дисперсионного анализа выходного параметра $Y$

Table 5. Results of the dispersive analysis of the output parameter Y

\begin{tabular}{|c|c|c|c|c|}
\hline \multirow{2}{*}{$\begin{array}{c}\text { Источники } \\
\text { дисперсии }\end{array}$} & \multicolumn{2}{|c|}{$\begin{array}{c}\text { В присутствии катализатора } \\
0,1 \mathrm{M} \mathrm{H}_{2} \mathrm{SO}_{4}\end{array}$} & $\begin{array}{r}\text { В присутствии катализатора } \\
\text { SBA-15 }\end{array}$ \\
\cline { 2 - 5 } & Эффективность $\mathrm{F}$ & $\begin{array}{c}\text { Уровень } \\
\text { значимости } P\end{array}$ & Эффективность $\mathrm{F}$ & $\begin{array}{c}\text { Уровень } \\
\text { значимости } P\end{array}$ \\
\hline $\mathrm{X}_{1}$ & 35,91 & 0,0093 & 130,09 & 0,0014 \\
\hline $\mathrm{X}_{2}$ & 5,06 & 0,1099 & 11,95 & 0,0407 \\
\hline $\mathrm{X}_{1}^{2}$ & 1,44 & 0,3156 & 22,68 & 0,0176 \\
\hline $\mathrm{X}_{1} \mathrm{X}_{2}$ & 0,37 & 0,5854 & 9,20 & 0,3477 \\
\hline $\mathrm{X}_{2}^{2}$ & 0,32 & 0,6123 & 1,23 & 98 \\
\hline $\mathrm{R}^{2}, \%$ & 94 & & \\
\hline
\end{tabular}

Ограничения области поиска решения в факторном пространстве для процессов, проводимых в присутствии катализатора $0,1 \mathrm{M} \mathrm{H}_{2} \mathrm{SO}_{4}$, составляют $90 \leq X_{1} \leq 130,60 \leq X_{2} \leq 420$.

Ограничения области поиска решения в факторном пространстве для процессов, проводимых в присутствии катализатора кислотномодифицированного SBA-15, составляют $100 \leq X_{1} \leq 150,120 \leq X_{2} \leq 360$.

Результаты дисперсионного анализа представлены в табл. 5.

Дисперсионный анализ выявил высокую значимость фактора $\mathrm{X}_{1}$ на достоверность модели процесса гидролиза арабиногалактана в присутствии катализатора $0,1 \mathrm{M} \mathrm{H}_{2} \mathrm{SO}_{4}$. На это указывает высокое значение дисперсионных отношений $\mathrm{F}$ и низкий уровень значимости $\mathrm{P}(<0,05)$. Зависимость $Y$ от $X_{1}$ и $X_{2}$ аппроксимирована неполным квадратичным уравнением регрессии:

$$
Y=-553,008+9,1481 \cdot X_{1}+0,0791667 \cdot X_{2}-0,0329573 \cdot X_{1}^{2} .
$$

Вклады источников дисперсии $X_{1} X_{2}$ и $X_{2}^{2}$ являются несущественными, поскольку отвечающие им значения $\mathrm{P}=0,5854$ и $\mathrm{P}=0,6123$ намного превышают принятый в технологических исследованиях «пороговый» уровень 0,05 . Соответственно, $X_{1} X_{2}$ и $X_{2}^{2}$ не включены в уравнение регрессии (6). На удовлетворительные прогностические свойства уравнения указывает величина коэффициента детерминации $R^{2}=94 \%$, а также относительно небольшие отклонения экспериментальных значений выходного параметра $Y$ от его прогнозируемых значений (рис. 8).

Поверхность отклика, соответствующая уравнению (6), изображена на рис. 9. Увеличение температуры гидролиза приводит к закономерному повышению степени конверсии арабиногалактана.

Аналогичным образом проанализировано влияние переменных факторов $X_{1}$ и $X_{2}$ в процессе гидролиза арабиногалактана на степень его конверсии $Y$ в присутствии кислотномодифицированного катализатора SBA-15. Дисперсионный анализ данных выявил существенный вклад в суммарную дисперсию выходного параметра трех источников дисперсии - $X_{1}, X_{2}, X_{1}^{2}$ (табл. 5). На это указывают высокие значения критериев эффективности $F$ и низкие уровни значимости $P(<0,05)$. Уровень значимости источника $X_{1} X_{2}$ фактически не превышает «пороговый» 0,05 . Вклад $X_{2}^{2}$ по формальным основаниям признан несущественным, и соответствующий член не 


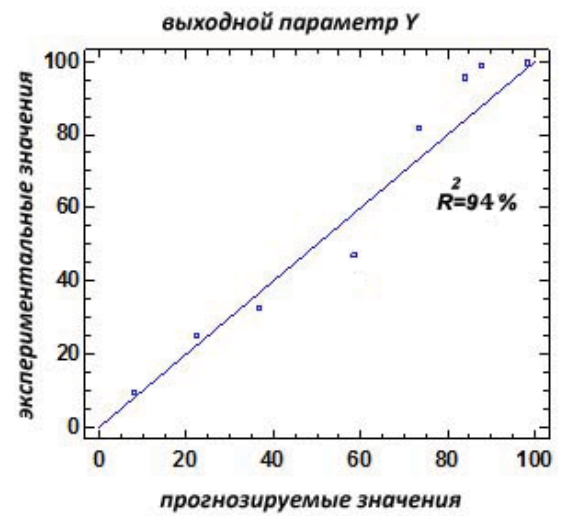

Рис. 8. Отклонения наблюдавшихся в эксперименте значений выходного параметра $Y$ от их расчетных значений согласно уравнению (6) для катализатора $0,1 \mathrm{M} \mathrm{H}_{2} \mathrm{SO}_{4}$

Fig. 8. Digressions of the experimentally observed values of the output parameter $\mathrm{Y}$ from their calculated values according to equation (6) for the catalyst $0,1 \mathrm{M} \mathrm{H}_{2} \mathrm{SO}_{4}$

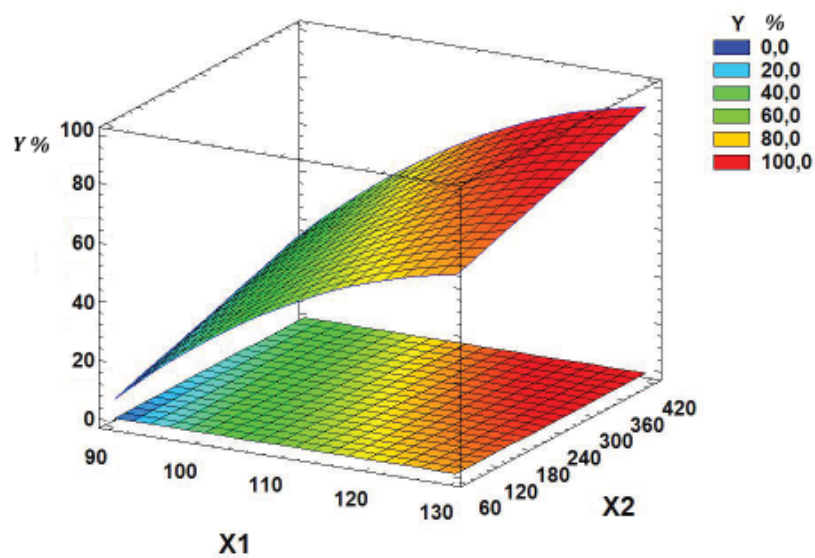

Рис. 9. Поверхность отклика выходного параметра $Y$ : зависимость степени конверсии арабиногалактана от температуры $\left(X_{1},{ }^{\circ} \mathrm{C}\right)$ и продолжительности $\left(X_{2}\right.$, мин) гидролиза в присутствии катализатора $0,1 \mathrm{M}$ $\mathrm{H}_{2} \mathrm{SO}_{4}$

Fig. 9. Response surface of output parameter $\mathrm{Y}$ : dependence of the degree of arabinogalactan conversion on temperature $\left(\mathrm{X}_{1},{ }^{\circ} \mathrm{C}\right)$ and reaction time $\left(\mathrm{X}_{2}, \mathrm{~min}\right)$ of hydrolysis in the presence of $0,1 \mathrm{M} \mathrm{H}_{2} \mathrm{SO}_{4}$ catalys

включен в уравнение регрессии (7). Зависимость $Y$ от $X_{1} u X_{2}$ аппроксимирована неполным квадратичным уравнением регрессии:

$$
Y=602,264-10,3113 \cdot X_{1}-0,41375 \cdot X_{2}+0,0433332 \cdot X_{1}^{2}+0,00406666 \cdot X_{1} \cdot X_{2} .
$$

Хорошие прогностические свойства уравнения (7) следуют из высокого значения коэффициента детерминации $R^{2}(98$ \%), а также относительно небольших отклонений экспериментальных значений выходного параметра от его прогнозируемых значений (рис. 10). Таким образом, уравнение (7) может рассматриваться в качестве адекватной математической модели степени конверсии АГ в присутствии твердого катализатора SBA-15.

$$
-180-
$$




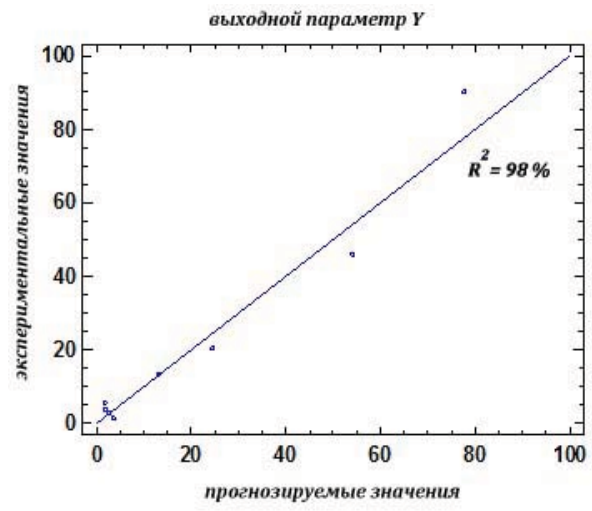

Рис. 10. Отклонения наблюдавшихся в эксперименте значений выходного параметра $Y$ от их расчетных значений согласно уравнению (7) для твердого катализатора SBA-15

Fig. 10. Digressions of the experimentally observed values of the output parameter $Y$ from their calculated values according to equation (7) for the catalyst SBA-15

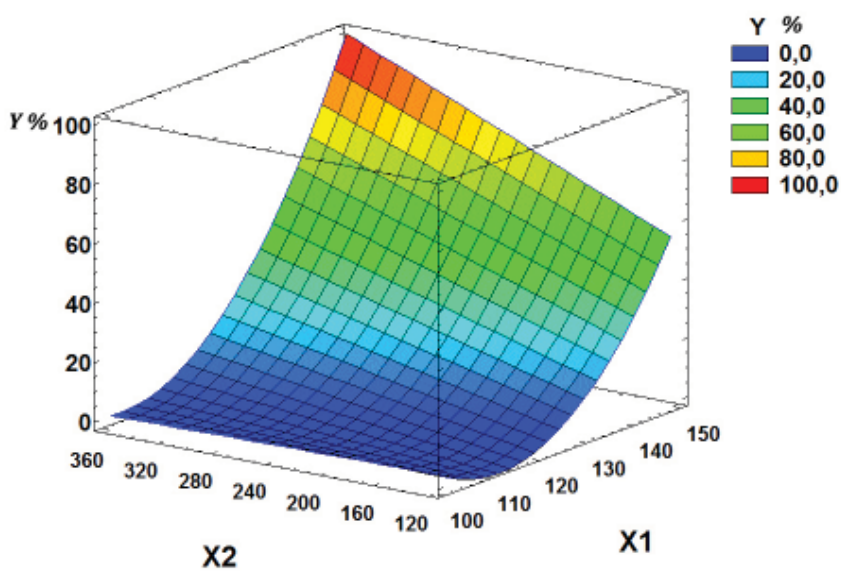

Рис. 11. Поверхность отклика выходного параметра $Y$ : зависимость степени конверсии арабиногалактана от температуры $\left(X_{1},{ }^{\circ} \mathrm{C}\right)$ и продолжительности $\left(X_{2}\right.$, мин) гидролиза в присутствии катализатора SBA-15

Fig. 11. Response surface of output parameter Y: dependence of the degree of arabinogalactan conversion on temperature $\left(\mathrm{X}_{1},{ }^{\circ} \mathrm{C}\right)$ and reaction time $\left(\mathrm{X}_{2}, \mathrm{~min}\right)$ of hydrolysis in the presence of SBA-15 catalyst

Поверхность отклика, соответствующая уравнению (7), изображена на рис. 11.

Уравнение (7) указывает на равнозначность и существенную степень влияния факторов $X_{1}$ и $X_{2}$ на выходной параметр $Y$. Увеличение температуры $\left(X_{1}\right)$ и продолжительности $\left(X_{2}\right)$ гидролиза АГ приводит к резкому увеличению степени конверсии арабиногалактана $(Y)$.

Оптимум, установленный для реакций, проводимых с растворенным катализатором 0,1M $\mathrm{H}_{2} \mathrm{SO}_{4}$, лежит внутри изученного факторного пространства, а для реакций, проводимых с катализатором SBA-15, прилегает к изученному факторному пространству.

Для процесса гидролиза арабиногалактана в присутствии катализатора $0,1 \mathrm{M} \mathrm{H}_{2} \mathrm{SO}_{4}$ полный гидролиз АГ прогнозируется при температуре $123,8{ }^{\circ} \mathrm{C}$ и продолжительности процесса 288 мин. 
Для процесса гидролиза арабиногалактана в присутствии твердого кислотного катализатора SBA-15 оптимальными являются температура $153{ }^{\circ} \mathrm{C}$ и продолжительность гидролиза 272 мин. Прогнозируемая степень конверсии АГ при этих условиях составляет $100 \%$.

\section{Заключение}

Изучено влияние температуры и продолжительности гидролиза арабиногалактана лиственницы в присутствии растворенных минеральных кислот $\mathrm{H}_{2} \mathrm{SO}_{4}$ и $\mathrm{HCl}$, а также твердых кислотных катализаторов Amberlyst 15, SBA-15 и Сибунит-4 на скорость образования арабинозы и галактозы. Методом газовой хроматографии изучен состав моносахаров, образующихся при кислотном гидролизе арабиногалактана.

Кинетический анализ показал, что константы скорости образования моносахаров увеличиваются в ряду катализаторов: Сибунит-4 $\left(150^{\circ} \mathrm{C}\right)<\mathrm{SBA}-15\left(150{ }^{\circ} \mathrm{C}\right)<$ Amberlyst $15\left(150{ }^{\circ} \mathrm{C}\right)$ $<0,1 \mathrm{M} \mathrm{H}_{2} \mathrm{SO}_{4}\left(130{ }^{\circ} \mathrm{C}\right)<0,1 \mathrm{M} \mathrm{HCl}\left(130^{\circ} \mathrm{C}\right)$. Значения энергии активации реакции образования арабинозы (65-91 кДж/моль) ниже, чем галактозы (112-140 кДж/моль).

Расчетными методами проведена оптимизация процесса гидролиза АГ в присутствии растворенного катализатора $0,1 \mathrm{M} \mathrm{H}_{2} \mathrm{SO}_{4}$ и твердого кислотного катализатора SBA-15. Установлено, что в присутствии $0,1 \mathrm{M} \mathrm{H}_{2} \mathrm{SO}_{4}$ при температуре $123,8{ }^{\circ} \mathrm{C}$ и продолжительности гидролиза 288 мин ожидаемая степень конверсии арабиногалактана составит около $100 \%$. Оптимальные режимные параметры процесса гидролиза АГ в присутствии SBA-15, при которых может быть достигнута близкая к $100 \%$ степень конверсии арабиногалактана, составляют $153{ }^{\circ} \mathrm{C}$ и 272 мин.

\section{Список литературы}

1. Медведева Е.Н., Бабкин В.А., Остроухова Л.А. Арабиногалактан лиственницы - свойства и перспективы использования (обзор). Химия растительного сырья 2003. №1, С.27-27. [Medvedeva E.N., Babkin V.A., Ostroukhova L.A. Arabinogalactan of larch - properties and prospects of use (review). Khimija Rastitel'nogo Syr'ja 2003. No.1, P.27-27. (In Russ.)]

2. Бабкин В.А., Неверова Н.А., Медведева Е.Н., Федорова Т.Е., Левчук А.А. Исследование физико-химических свойств арабиногалактана различных видов лиственницы. Химия растительного сырья 2015. №2, С. 29-35. [Babkin V.A., Neverova N.A., Medvedeva E.N., Fedorova T.E., Levchuk A.A. The study of the physico-chemical properties of arabinogalactan of various species of larch. Khimija Rastitel'nogo Syr'ja 2015.No.2, P. 29-35. (In Russ.)]

3. Dion C., Chappuis E., Ripoll Ch. Does larch arabinogalactan enhance immune function? A review of mechanistic and clinical trials. Nutrition \& Metabolism 2016. No.13, P. 28

4. Riede L., Grube B., Gruenwald J. Larch arabinogalactan effects on reducing incidence of upper respiratory infections. Current Medical Research and Opinion 2013. Vol. 29, P. 251-258.

5. Dushkin A.V., Meteleva E.S., Tolstikova T. G., Khvostov M.V., Tolstikov G.A. Mechanochemical preparation and properties of water-soluble intermolecular complexes of polysaccharides and $\beta$-cyclodextrin with pharmaceutical substances. Chemistry for Sustainable Development 2010. Vol. 18, P. 631-640.

6. Stephen A.M., Phillips G.O., Williams P.A. Food polysaccharides and their applications. CRC. Taylor and Francis Group. Boca Raton, London, NW. 2006. 734 p. 
7. Lanzer P., Lipton M. Diagnostics of vascular diseases. Principles and Technology. Springer. 1997. $361 \mathrm{p}$.

8. Schlief R., Alhassan A., Wiggins J., Schumann W., Niendorf H.-P. Safety of the galactosebased ultrasound contrast agent Levovist. Academic radiology 2002. Vol. 9. (1), P. 240-242.

9. Helanto M., Kiviharju K., Granström T., Leisola M., Nyyssölä A. Biotechnological production of L-ribose from L-arabinose. Appl Microbiol Biotechnol 2009. Vol. 83, P. 77-83.

10. Kusema B. T., Xu Ch., Mäki-Arvela P., Willför S., Holmbom B., Salmi T., Murzin D. Yu. Kinetics of acid hydrolysis of arabinogalactans. Int. Journal of Chem. Reactor Engineering 2010. Vol. 8, P. 1-18.

11. Dhepe P.L., Sahu R. A solid-acid-based process for the conversion of hemicelluloses. Green Chemistry 2010. Vol. 12, P. 2153-2156.

12. Kusema B.T., Hilmann G., Mäki-Arvela P., Willför S., Holmbom B., Salmi T., Murzin D.Yu. Selective hydrolysis of arabinogalactan into arabinose and galactose over heterogeneous catalysts. Catal Lett 2011. Vol. 141, P. 408-412.

13. Murzin D.Yu., Murzina E.V., Tokarev A., Shcherban N.D., Wärnå J., Salmi T. Arabinogalactan hydrolysis and hydrolytic hydrogenation using functionalized carbon materials. Catalysis Today 2015. Vol. 257, P. 169-176.

14. Demma C.P., Pagliaro M., Elmekawy A., Brown D.R., Verschuren P., Shiju N.R., Rothenberg G. Hemicellulose hydrolysis catalysed by solid acids. Catal Sci Technol 2013. Vol. 3, P. 2057-2061.

15. Pang J., Wang A., Zheng M., Zhang T. Hydrolysis of cellulose into glucose over carbons sulfonated at elevated temperatures. Chem. Commun 2010. Vol. 46, Р. 6935-6937.

16. Козлова С.А., Парфенов В.А., Кирик С.Д. Сорбционные свойства мезопористых силикатов, функционализированных тиольными группами. Журнал Сибирского федерального университета. Техника и технологии 2015. T. 8 (4), C. 494-506. [Kozlova S.A., Parfenov V.A., Kirik S.D. Adsorption Properties of Thiol-Functionalized Mesoporous Silica. Journal of Siberian Federal University. Engineering \& Technologies 2015. T.8 (4), P. 494-506. (In Russ.)]

17. Song S.-W., Hidajat K., Kawi S.. Functionalized SBA-15 Materials as carriers for controlled drug delivery: influence of surface properties on matrix-drug interactions. Langmuir 2005. 21 (21), P. 9568-9575.

18. Melero J. A., Grieken R., Morales G. Advances in the synthesis and catalytic applications of organosulfonic-functionalized mesostructured materials. Chem. Rev. 2006. V.106, P. 3790-3812.

19. Ruiz-Matute A.I., Hernandez-Hernandez O., Rodriguez-Sanchez S., Sanz M.L., MartinezCastro I. Derivatization of carbohydrates for GC and GC-MS analyses. J. Chromatogr. B. 2011. Vol. 879, P. 1226-1240.

20. Salmi T., Murzin D. Yu., Maki-Arvela P., Kusema B., Holmbom B., Willfor St. Kinetic modeling of hemicellulose hydrolysis in the presence of homogeneous and heterogeneous catalysts. AIChE Journal 2014. Vol. 60 (3), P. 1066-1077.

21. Lavarack P.B., Griffin G.J., Rodman D. The acid hydrolysis of sugarcane bagasse hemicellulose to produce xylose, arabinose, glucose and other products. Biomass Bioenergy 2002. Vol. 23, P. 367-380.

22. Пен Р.3. Планирование эксперимента в Statgraphics Centurion. Красноярск: СибГТУ. 2014. 293 c. [Pen R.Z. Planning an experiment in Statgraphics Centurion. Krasnoyarsk. 2014. 293 p. (In Russ.)] 